\title{
A COMPARATIVE STUDY OF THE EFFECTS OF VIBRATION AND ELECTRICAL STIMULATION THERAPIES ON THE ACCELERATION OF WOUND HEALING IN DIABETIC ULCERS
}

\author{
Yunita Sari*, Saryono Saryono*, Eman Sutrisna**, Hartono Hartono*** \\ * Department of Nursing, Jenderal Soedirman University, Purwokerto, Indonesia \\ ** Department of Medical Science, Jenderal Soedirman University, Purwokerto, Indonesia \\ *** Department of Physics Science, Jenderal Soedirman University, Purwokerto, Indonesia \\ E-mail: yunita-tky@umin.ac.jp/sasa.yunita@gmail.com
}

\begin{abstract}
Introduction: Diabetic ulcers accompanied by ischemia is difficult to treat. Such ulcers require therapy that can improve the blood flow. Previous studies have revealed that two therapies could improve blood flow and accelerate the healing of diabetic ulcers; vibration and electrical stimulation (ES). However, it is unknown which of these two therapies is best at accelerating wound healing in diabetic ulcers. The purpose of this study was to compare both therapies in relation to accelerating the wound healing of diabetic ulcers. Methods: This study was an experimental study involving diabetic rats. The rats were divided into two groups: vibration and ES. Vibration and ES were applied for 10 minutes per day for 7 days. Wound size, inflammation, intensity of fibroblast infiltration, area of necrosis and degree of re-epithelialisation were compared. The difference in wound size was analysed using an independent t-test, while the histological data were analysed using a Mann-Whitney U-test. Results: On day 5 onwards, there was a thin slough in the ES group which was not present in the vibration group. Day 4 onwards and the wound size was significantly smaller in the vibration group than in the ES group. The intensity of inflammation was significantly less, and the degree of fibroblast infiltration was significantly higher in the vibration group compared with the ES group. Re-epithelialisation was more advanced in the vibration group than the ES group. Conclusions: Our study revealed that wound healing in diabetic ulcers following vibration was better than after ES. We suggest that nurses should use vibration rather than ES in clinical settings.
\end{abstract}

Keywords: complementary therapy, diabetic ulcer, electrical stimulation, vibration, wound healing

\section{INTRODUCTION}

Indonesia has the tenth highest proportion of people with diabetes mellitus (DM) in the world (Shaw, Sicree and Zimmet, 2010). It is predicted that Indonesia will become number six by 2030 (Shaw, Sicree and Zimmet, 2010). Soewondo, Ferrario and Tahapary (2013) revealed that the prevalence of patients with DM in Indonesia had increased by $11 \%$ over 19 years, although this figure is likely to be higher since there are many unreported cases (Yusuf et al., 2016).

Diabetes mellitus causes many complications. Patients have a risk of limb amputation at a rate that is 40 times higher than people without DM (Brechow et al., 2013). After amputation, patients with DM also have a higher risk of limb re-amputation and rate of mortality (Moulik, Mtonga and Gill, 2003; Izumi et al., 2006). Armstrong, Wrobel and Robbins (2007) showed that the prevalence of deaths due to diabetic foot ischemia was higher than that due to cancer.

Considering the impact of diabetic ulcers on patients, a therapy that accelerates wound healing is urgently required. Wu et al., 2007 revealed that diabetic ulcers that heal with difficulty are accompanied by impaired blood flow (ischemia).

The presence of ischemia impairs the wound healing process, especially the angiogenetic phase, thus a therapy that improves blood flow would be of great benefit, including the use of drugs which act as vasodilators that improve blood flow or induce angiogenesis such as prostaglandins or basic fibroblast growth factor (Addison et al., 1972; Lees, 1994). However, the continuous administration of these drugs causes side effects such as cramping, the vasoconstriction of blood vessels and the acceleration of osteogenesis (Nagase et al., 2007). Because most patients with diabetic foot ulcers also have other complications due to high blood glucose, a therapy that has minimal side effects is not invasive and is comfortable for patients is required.

Previous studies have shown that two complementary therapies that are safe for application to patients are vibration and electrical stimulation (ES). A previous study revealed that a low vibration frequency can improve blood flow (Nakagami et al., 2007), and accelerate healing of stage I pressure ulcers (Arashi et al., 2010), deep tissue injury 
(Sari, et al., 2015) and diabetic ulcers (Sari, Sutrisna and Hartono, 2016). Sari et al., (2015) revealed that the reduction of hypoxia and reduction of activation of matrix metalloproteinase-2 and matrix metalloproteinase-9 are the mechanisms that are responsible for the acceleration of wound healing following vibration.

Studies reveal that ES has been utilised for many health purposes because it can improve blood flow. Humans create a type of electricity called bioelectricity. Following an injury to the skin, a low current flows between the skin and underlying tissue, which is called the current of injury. This is important during the wound healing process (Kim, Cho and Lee, 2014). The electric current which is used in ES is a low current (microAmpere, $\mu \mathrm{A}$ ).

Thus, the low current of ES therapy reflects the bioelectric current created by the body (Ud-Din and Bayat, 2014). Results of studies both in vitro and in vivo reveal that ES improves the healing process by promoting keratinocyte migration, improving wound perfusion, stimulating collagen synthesis (Kim, Cho and Lee, 2014), and inducing angiogenesis (Liebano and Machado, 2014). (Liebano and Machado, 2014). A previous in vitro study revealed that ES could also reduce inflammation (Cho et al., 2000). In results similar to the effect of vibration, previous studies have also shown that ES accelerates wound healing in pressure, ischemic and diabetic ulcers (Eriksson et al., 1981; Goldman et al., 2003; Koel and Houghton, 2014).

Based on the above studies, both vibration and ES could improve wound healing. However, up to the present, there is no study that compares the effectiveness of the two complementary therapies, therefore, which therapy is better for accelerating wound healing of diabetic ulcer is still unknown.

\section{MATERIALS AND METHODS}

\section{Research Design}

This was an experimental study utilising post-test only, using a control group design approach.

\section{Electrical Stimulation Device (Figure 1)}

Electrical stimulation consisted of two main parts, the electrodes and power supply. The electrodes served as a distributor of

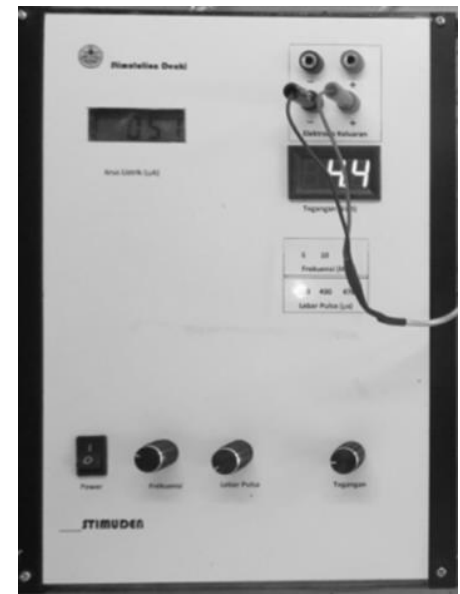

1. Electrical stimulation device

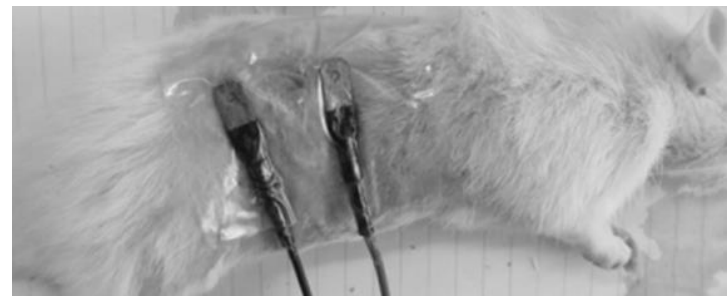

Figure 2. The application of ES in rat skin

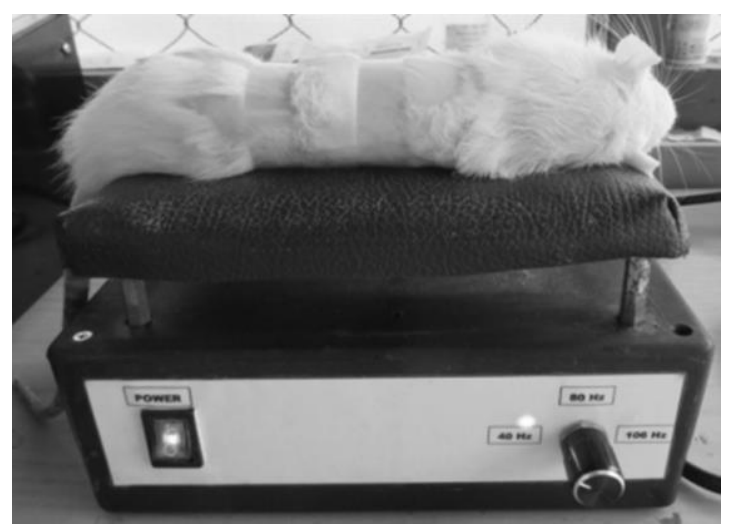

Figure 3. Rat was placed on the vibrating device. The wound is at the centre of the vibrating device.

electrical current to the skin and were constructed from corrosion-resistant metal that could easily be attached to the skin. The power supply provided electric current to both electrodes. The current generated was a square wave of electrical pulses whose amplitude and frequency could be varied (Sari, Sutrisna and Hartono, 2017).

The electrodes were attached to the skin as shown in Figure 2. Based on previous research, ES was applied for 10 minutes every day for 7 days $(20 \mathrm{~Hz}, 320 \mu \mathrm{s}, 50 \mu \mathrm{A})$ (Sari, Sutrisna and Hartono, 2017). 


\section{Vibration Device}

The vibration device which was used in this study was originally constructed by our research team (Sari, Sutrisna and Hartono, 2016). In brief, the vibration bed consisted of 3 vibrating motors and its frequency can be varied by changing the velocity. The application of the use of vibration bed for the rat can be seen in Figure 3. The rats were given an application of vibration for 10 minutes once a day for 7 days.

\section{Animal}

This study used male Wistar rats aged 12-14 weeks. The rat's body weight was in the range of 190-220 grams. The rats had free access to food and drink. The protocol of this study was approved by the research committee ethics for an animal study, of the Faculty of Medicine, Jenderal Soedirman University (1208/KEPK/III/2017).

The rats were divided into two groups, vibration-treated and electrical stimulationtreated. Every day, the wounds were washed with saline in both groups prior to being covered with a film dressing.

\section{Induction of Rats}

The rats were acclimatised for 7 days before the induction of diabetes by injection of Alloxan Monohydrate (Sigma Aldrich, USA) at a dose of $90 \mathrm{mg} / \mathrm{kg}$. Blood was drawn from the tail vein 4 days after induction to assess whether the blood glucose concentration had increased. The rats were considered diabetic when their blood glucose was greater than 250 $\mathrm{mg} / \mathrm{dl}$. The rats were shaved the day prior to wounding. The rats were anesthetised with Ketamile (25-30 mg/kg body weight) during the shaving and wounding procedures.

The procedure of wounding was according to the previous publication (Sari et al., 2015a) The diameter of each wound was $1 \mathrm{~cm}$, extending to the Panniculus carnosus. The wounds were cleaned with normal saline, dried with gauze then covered with a parafilm dressing. The wound was monitored daily from day 0 to 7 and recorded with a digital camera.

\section{Tissue Staining}

The rats were sacrificed on day 7 using an overdose of ketamile. The tissue samples were fixed in $10 \%$ formalin then processed and embedded into paraffin. The samples were sectioned and then stained with a hematoxylin and eosin (H\&E). Sections were observed using a light microscope. The inflammation and infiltration of inflammatory cells were indicated by blue staining in the $\mathrm{H} \& \mathrm{E}$ sections.

\section{Wound Size}

The size of the wound was measured by using ImageJ software from the National Health Institute. The wound area was determined based on the inner wound margins (Ueda et al., 2010) The relative wound areas were determined as (day $\mathrm{n}$ area - day 0 area) / (day 0 area). (Ueda et al., 2010)

\section{Reepithelialisation}

Reepithelialisation was indicated by the presence of new epithelial tissue in the epidermis layer. Reepithelialisation was observed with a light microscope. The result of the study was described qualitatively.

\section{Statistical Analysis}

Statistical analysis was performed by SPSS software, version 16. The data of the wound size was analysed by an independent ttest. The histological result was analysed by a Mann-Whitney U-test. The value of $p<0,05$ was considered to be significant.

\section{RESULTS}

The result of the macroscopical findings could be seen in Figure 4. On day 0, the visual appearance of the wound was similar in both groups. On day 1 to day 3 , the wound base in both groups started to be filled with granulation tissue. On day 3 , the wound size in the vibration group tended to be smaller

Table 1. Intensity of inflammation and fibroblast between vibration and ES group

\begin{tabular}{lcc}
\multicolumn{1}{c}{ group } & \\
\hline \multicolumn{1}{c}{ Groups } & PMNs & Fibroblas \\
\hline Vibration & $2^{*}$ & $3^{*}$ \\
Electrical & 3 & 2 \\
stimulation & & \\
\hline
\end{tabular}

Values indicated median score

Rating scale : $0=$ absent, $1=$ occasional, $2=$ moderate, $3=$ abundant, $>3=$ very abundant $* \mathrm{P}<0.05$

PMNs = polymorphonuclear neutrophils 


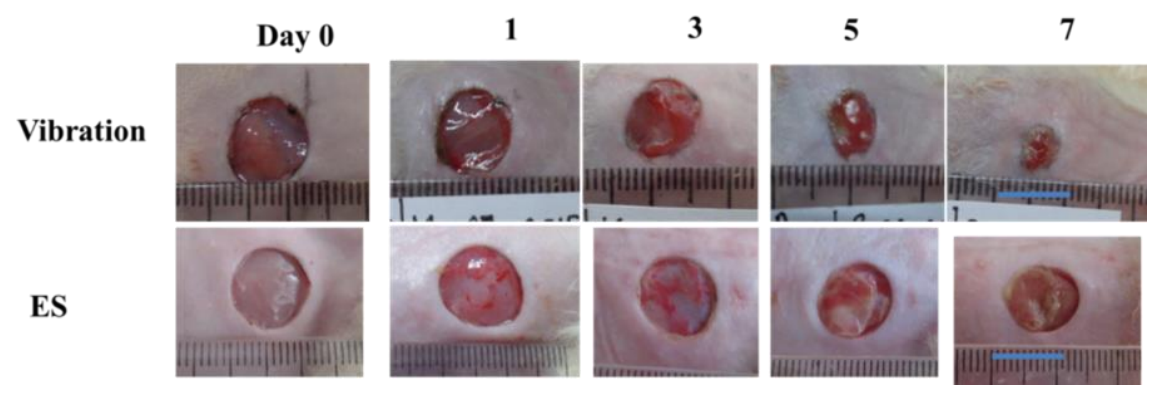

Figure 4. Macroscopical findings of the wounds treated with vibration (upper picture) and Electrical stimulation (lower picture) $(\mathrm{bar}=1 \mathrm{~cm})$

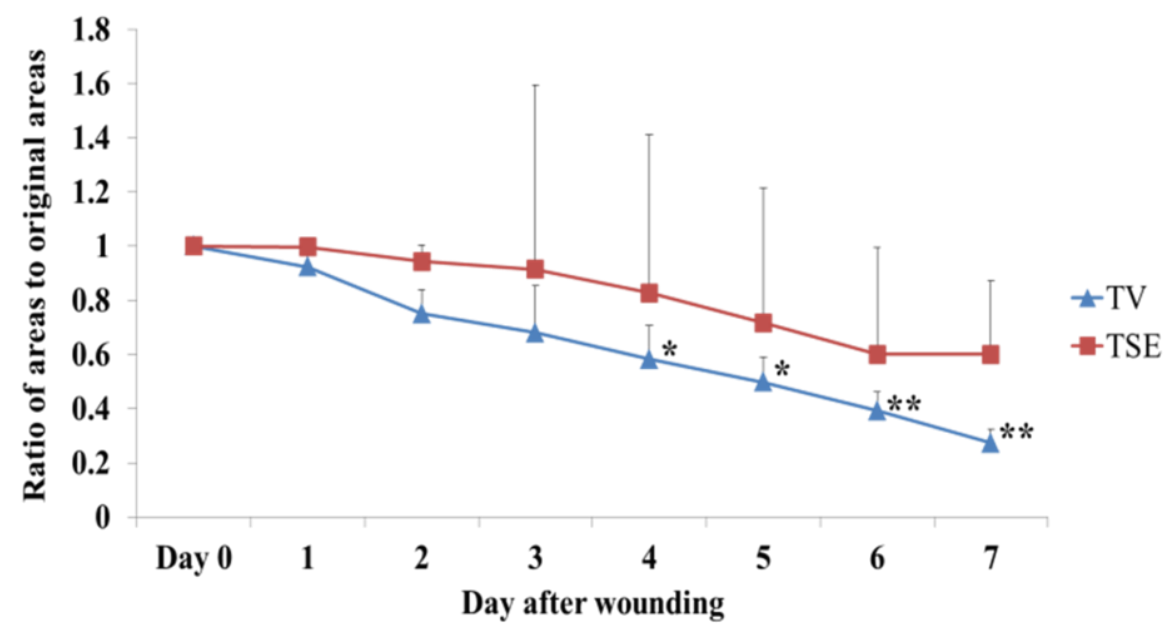

Figure 5. The comparison of the wound size between the wounds treated with vibration and electrical stimulation $(* \mathrm{P}<0.05, * * \mathrm{P}<0.01)$

compared with the ES group. On day 5, the granulation tissue in both groups was increased. However, there was a thin layer of slough in the ES group, which was not present in vibration group. On day 7 , the thin layer of the slough was still present in the ES group.

The difference of the wound size between two groups could be seen in Figure 5 . There was no significant difference in wound size between vibration therapy and ES from day 0 to day 3 . However, the wound size in the vibration group was significantly smaller than in the ES group on day 4 to day $7(\mathrm{P}=0,011$ on day $4, \mathrm{P}=0.025$ on day $5, \mathrm{P}=0.005$ on day 6 , $\mathrm{P}=0.0001$ on day 7 ).

The microscopical difference between the vibration and ES group in the epidermis and dermis layers can be seen in Figure 6. The intensity of inflammation in both the epidermis and dermis layer in the vibration group was less compared to the inflammation in the ES group. The intensity of the fibroblasts was higher in the vibration group than in the ES group. The difference in the histological findings can be seen in Table 1. The intensity of inflammation was significantly less in the vibration compared with the ES group $(\mathrm{P}=0,034)$, and the fibroblast intensity was higher in the vibration compared with the ES group $(\mathrm{P}=0,045)$.

\section{DISCUSSION}

This study is the first study in the literature that compares vibration and electrical stimulation in accelerating the wound healing of diabetic ulcers. In this study, we found that wounds heal better if treated with vibration therapy compared with electrical stimulation.

The previous study revealed that ES could reduce inflammation, improve blood flow, reduce the bacterial burden, reduce pain and edema, decrease muscle spasms, and improve TGF- $\beta 1$, collagen-I, and muscle 
contraction (Demir, Balay and Kirnap, 2004; Sebastian et al., 2011; Kim, Cho and Lee, 2014; Torkaman, 2014).

Recent research by the author has shown that compared with the standard treatment, wounds treated with ES showed a reduction in inflammation and an increase in re-epithelialisation (Sari, Sutrisna and Hartono, 2017). A reduction in inflammation following ES in diabetic ulcers might be due to the ability of ES to enhance phagocytosis (Cho et al., 2000). The improvement of reepithelialization might be due to the ability of ES to promote keratinocyte migration (Kim, Cho and Lee, 2014).

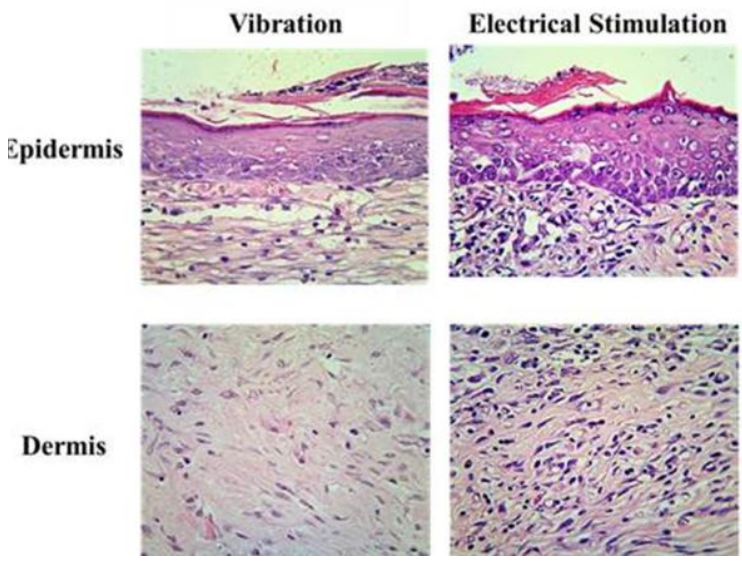

Figure 6. The histological findings of the epidermis and dermis layer between the vibration and ES groups. Hematoxylin and Eosyn staining in the epidermis layer (upper part) and dermis (lower part) between vibration and electrical stimulation (magnification of 400X)
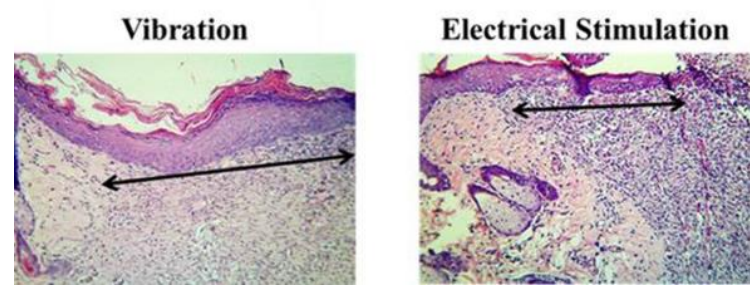

Figure 7. Re-epithelialisation between the vibration and ES group. Reepithelialisation was longer in the vibration group than in electrical stimulation group (arrow line indicates length of reepithelialisation, magnification of $100 \mathrm{X}$ )
Based on previous studies, vibration could also accelerate the healing of diabetic ulcers, such as in pressure ulcers stage I, deep tissue injuries, and diabetic ulcers (Arashi et al., 2010; Sari, Sanada, et al., 2015; Sari, Sutrisna and Hartono, 2016). Vibration therapy that can accelerate the healing of diabetic ulcer is a vibration which is applied at a low frequency. If the vibration is applied at a high frequency, it will cause tissue damage (Sari, Sutrisna and Hartono, 2016). A high frequency of vibration might cause an excessive increase of reactive oxygen species and nitric oxide that causes the vasoconstriction of blood vessels (Hughes et al., 2009).

In this study, the author used a vibration of $40 \mathrm{~Hz}$ and ES with a frequency of $20 \mathrm{~Hz}$, pulse width of $320 \mathrm{~Hz}$ at a current of 50 $\mu \mathrm{A}$. These values were chosen after previous studies by the author, and other researchers found that wounds healed using those ranges of frequency and currents (Torkaman, 2014; Sari, Sutrisna and Hartono, 2017). The previous study revealed that a vibration below $50 \mathrm{~Hz}$ could accelerate the wound healing of chronic ulcers (Arashi et al., 2010; Sari, et al., 2015). The author investigated a vibration frequency range and determined that a frequency of $40 \mathrm{~Hz}$ accelerated the healing of diabetic ulcers (Sari, Sutrisna and Hartono, 2016). In relation to ES, the author also found that the frequency of $20 \mathrm{~Hz}$, the pulse width of $320 \mathrm{~Hz}$ and a current of $20 \mu \mathrm{A}$ could accelerate the healing of diabetic ulcers (Sari, Sutrisna and Hartono, 2017).

In this study, we found that wound healing in diabetic ulcers using vibration was better than using ES. The wound sizes were smaller when treated with vibration and showed a greater reduction in inflammation compared with the wounds treated using ES. However, the mechanism for this difference remains unknown. In this study, the vibration was experienced by the entire body, and so it is possible that blood flow might increase systemically and not only to the wound area. However, blood flow is likely to increase only in the wound area during ES, since the electrodes were placed directly on the wound. In patients with DM, increased blood flow around the body is important since high blood glucose frequently causes plaque that can result in impaired blood flow. Another study is needed to elucidate the mechanism as to why 
the wound healed better in vibration compared with in ES.

In this study, all of the animals with diabetic ulcers survived during the observation of wound healing. However, ES can sometimes cause skin tearing. It is, therefore, reasonable to suggest that vibration therapy is safer than ES.

The results of this study are very important since it is the first study that establishes that vibration accelerates wound healing in diabetic ulcers to a greater extent than ES. Nurses should consider using complementary therapies such as vibration to accelerate the healing of diabetic ulcers instead of using ES.

\section{CONCLUSIONS}

This study is the first study in the literature to investigate the comparison of the effect of vibration therapy and electrical stimulation therapy in accelerating the wound healing of diabetic ulcers. In this study, we revealed that wounds treated with vibration therapy healed better than by ES therapy.

Besides, this is the first study in the literature that compares the effect of vibration therapy with electrical stimulation therapy in relation to the wound healing of diabetic ulcers. We have demonstrated that the wounds treated with vibration therapy healed better than by ES therapy, and so we suggest that nurses in clinical settings use complementary vibration therapy instead of ES when treating wounds.

In this study, we used animals since we wanted to investigate the healing of the wounds in diabetic ulcers in deep tissue. In the future, we will compare the effects of vibration and ES in human subjects.

\section{Acknowledgment}

This study was funded by the Penelitian Unggulan Perguruan Tinggi grant from the Ministry of Research, Technology and Higher Education. The researcher would like to thank Wawan Setiawan and Genti Larasati for their assistance during the animal experiments.

\section{REFERENCES}

Addison, G. M. et al. (1972) 'Prostaglandin E1 in severe', pp. 155-156.

Arashi, M. et al. (2010) 'Vibration therapy accelerates healing of Stage I pressure ulcers in older adult patients', Advances in skin \& wound care, 23(7), pp. 321-327. doi: 10.1097/01.ASW.0000383752.39220 .fb.

Armstrong, D. G., Wrobel, J. and Robbins, J. M. (2007) 'Guest editorial: Are diabetes-related wounds and amputations worse than cancer?', International Wound Journal, 4(4), pp. 286-287. doi: 10.1111/j.1742481X.2007.00392.x.

Brechow, A. et al. (2013) 'Improving major amputation rates in the multicomplex diabetic foot patient: focus on the severity of peripheral arterial disease', Therapeutic Advances in Endocrinology and Metabolism, 4(3), pp. 83-94. doi: $10.1177 / 2042018813489719$.

V C Lees, T. P. D. F. (1994) 'A freeze-injured skin graft model for the quantitative study of basic fibroblast growth factor and other promoters of angiogenesis in wound healing', $\mathrm{Br} \mathrm{J}$ Plast Surg, 47, pp. 349-359.

Cho, M. R. et al. (2000) 'Integrin-dependent human macrophage migration induced by oscillatory electrical stimulation.', Annals of biomedical engineering, 28(3), pp. 234-43. doi: 10.1114/1.263.

Demir, H., Balay, H. and Kirnap, M. (2004) 'A comparative study of the effects of electrical stimulation and laser treatment on experimental wound healing in rats.', Journal of rehabilitation research and development, 41(2), pp. 147-54. doi: 10.1682/JRRD.2004.02.0147.

Eriksson, E. et al. (1981) 'Effect of electrical stimulation on human skeletal muscle.', International journal of sports medicine, 2(1), pp. 18-22. doi: 10.1055/s-2008-1034578.

Goldman, R. et al. (2003) 'Electrotherapy promotes healing and microcirculation of infrapopliteal ischemic wounds: a prospective pilot study.', Advances in skin \& wound care, 17(6), pp. 284-294. doi: 10.1097/00129334-20040700000010.

Hughes, J. M. et al. (2009) 'Increased oxidant activity mediates vascular 
dysfunction in vibration injury.', The Journal of pharmacology and experimental therapeutics, 328(1), pp. 223-30. doi: 10.1016/S07494041(09)79206-1.

Izumi, Y. et al. (2006) 'Risk of reamputation in diabetic patients stratified by limb and level of amputation: A 10-year observation', Diabetes Care, 29(3), pp. $566-570$ doi: 10.2337/diacare.29.03.06.dc05-1992.

Kim, T. H., Cho, H. and Lee, S. M. (2014) 'High-Voltage Pulsed Current Stimulation Enhances Wound Healing in Diabetic Rats by Restoring the Expression of Collagen, $\alpha$-Smooth Muscle Actin, and TGF- $\beta 1$ ', The Tohoku Journal of Experimental Medicine, 234(1), pp. 1-6. doi: 10.1620/tjem.234.1.

Koel, G. and Houghton, P. E. (2014) 'Electrostimulation: Current Status, Strength of Evidence Guidelines, and Meta-Analysis', Advances in Wound Care, 3(2), pp. 118-126. doi: 10.1089/wound.2013.0448.

Liebano, R. E. and Machado, A. F. P. (2014) 'Vascular Endothelial Growth Factor Release Following Electrical Stimulation in Human Subjects.', Advances in wound care, 3(2), pp. 98-103. doi: 10.1089/wound.2013.0427.

Moulik, P. K., Mtonga, R. and Gill, G. V. (2003) 'Amputation and mortality in new-onset diabetic foot ulcers stratified by etiology', Diabetes Care, 26(2), pp. 491-494. doi: 10.2337/diacare.26.2.491.

Nagase, T. et al. (2007) 'Heterotopic ossification in the sacral pressure ulcer treated with basic fibroblast growth factor: coincidence or side effect?', Journal of Plastic, Reconstructive \& Aesthetic Surgery, 60(3), pp. 327-329. doi: 10.1016/j.bjps.2005.11.043.

Nakagami, G. et al. (2007) 'Effect of vibration on skin blood flow in an in vivo microcirculatory model', BioScience Trends, 1(3), pp. 161-166.

Sari, Y., Saryono, et al. (2015) 'Modifikasi Pompa ASI Sebagai Terapi Luka Bertekanan Negatif Untuk Mempercepat Penyembuhan Luka
Diabetes', 10(1), pp. 104-111.

Sari, Y., Sanada, H., et al. (2015) 'Vibration inhibits deterioration in rat deeptissue injury through HIF1-MMP axis', Wound Repair and Regeneration, 23(3), pp. 386-393. doi: 10.1111/wrr.12286.

Sari, Y., Sutrisna, E. and Hartono (2016) 'Pengaruh Frekuensi Vibrasi terhadap Penyembuhan Luka Diabetes The Provision of Different Vibration Frequency to Accelerate Diabetic Wound Healing', Jurnal Keperawatan Padjajaran, 4, pp. 117-126.

Sari, Y., Sutrisna, E. and Hartono (2017) 'The Effect of Electrical Stimulation on Promoting Wound Healing in Diabetic Ulcer', in The $3 r d$ International Conference on Nursing (ICON) 2017. Malang, Indonesia.

Sebastian, A. et al. (2011) 'Acceleration of cutaneous healing by electrical stimulation: Degenerate electrical waveform down-regulates inflammation, up-regulates angiogenesis and advances remodeling in temporal punch biopsies in a human volunteer study', Wound Repair and Regeneration. Mosby, Inc., 19(6), pp. 693-708. doi: 10.1111/j.1524-475X.2011.00736.x.

Shaw, J. E., Sicree, R. A. and Zimmet, P. Z. (2010) 'Global estimates of the prevalence of diabetes for 2010 and 2030', Diabetes Research and Clinical Practice, 87(1), pp. 4-14. doi: 10.1016/j.diabres.2009.10.007.

Soewondo, P., Ferrario, A. and Tahapary, D. (2013) 'Challenges in diabetes management in Indonesia: a literature review', Globalization and Health, 9(1), p. 63. doi: 10.1186/1744-8603-9-63.

Torkaman, G. (2014) 'Electrical Stimulation of Wound Healing: A Review of Animal Experimental Evidence', Advances in Wound Care, 3(2), pp. 202-218. doi: 10.1089/wound.2012.0409.

Ud-Din, S. and Bayat, A. (2014) 'Electrical Stimulation and Cutaneous Wound Healing: A Review of Clinical Evidence', Healthcare, 2(4), pp. 445-467. doi: 
Jurnal Ners Vol. 12 No. 2 Oktober 2017: 253-260

10.3390/healthcare2040445.

Ueda, K. et al. (2010) 'A possible animal model for critical colonisation.', Journal of wound care, 19(7), pp. 295-300.

$\mathrm{Wu}$, S. C. et al. (2007) 'Foot ulcers in the diabetic patient, prevention and treatment', Vascular Health and Risk
Management, 3(1), pp. 65-76. doi: $10.3310 /$ hta13540.

Yusuf, S. et al. (2016) 'Prevalence and Risk Factor of Diabetic Foot Ulcers in a Regional Hospital , Eastern Indonesia', Open Journal of Nursing, 6(January), pp. 1-10. doi: 10.4236/ojn.2016.61001. 